\title{
New Editors, 2013
}

Published online: 12 February 2013

(C) Springer Science+Business Media New York 2013

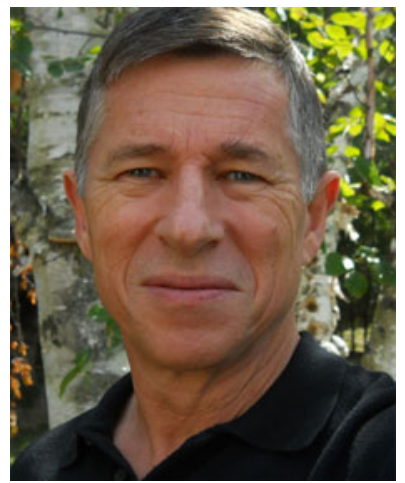

Stephen K. Sunter graduated from the University of Waterloo in 1978 with a Bachelor of Applied Science in electrical engineering. He worked in mixed-signal IC design from 1977 to 1990 at Bell-Northern Research and Nortel. Then he moved to Australia to develop digital DFT and ATPG solutions at GEC-Plessey Telecommunications from 1990 to 1992 , returning afterwards to Ottawa to manage mixed-signal test engineering at Nortel until 1995. In 1996, he became engineering director of mixed-signal DFT at LogicVision before it was acquired by Mentor Graphics in 2009, where he continues to hold that position.

In addition to 25 U.S. patents, Steve has published over 40 journal/conference papers on mixed-signal DFT/BIST topics, three of which won Best Paper or Honorable Mention awards. He has contributed chapters to four books about mixed-signal DFT and BIST, one of which was described in an IEEE Design \& Test review as, "a model of how a tutorial chapter should be written." He has also presented over a dozen tutorials, to audiences of 20 120 people, each lasting between an hour and a day, and written articles in magazines such as EDN, Evaluation Engineering, and Computer Design. He is an active member of the Working Groups for the IEEE mixedsignal DFT-related standards: 1149.4, 1149.6, and 1149.8.1. He has served on the Program Committees of the International Test Conference (ITC) and VLSI Test Symposium (VTS) for over 15 years, on the Program Committees for the Test
Technology Educational Program (TTEP) and the Design Automation and Test in Europe (DATE) conference for 5 years, and has thrice served as Program Chair/Co-Chair for the International Mixed Signals Testing Workshop (IMSTW). His research interests include: methods and automation for DFT, especially BIST, for analog and mixed-signal circuits; parametric aspects of digital circuits, especially $\mathrm{I} / \mathrm{O}$ pin circuitry; and analog fault grading.

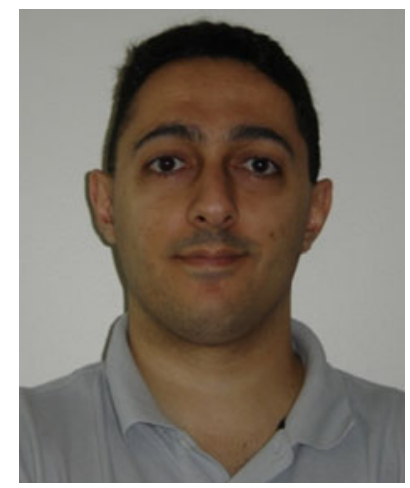

Theocharis (Theo) Theocharides is an Assistant Professor in the Department of Electrical and Computer Engineering, at the University of Cyprus. Theocharis received his Ph.D. in Computer Engineering from Penn State University, working in the areas of low-power computer architectures and reliable system design. Theocharis was honored with the Robert M. Owens Memorial Scholarship in May 2005. He has been with the Electrical and Computer Engineering department at the University of Cyprus since 2005, where he directs the Embedded and Application-Specific Systemson-Chip Laboratory. His current research focuses on the development of low-power and reliable on-chip applicationspecific architectures, low-power VLSI design, embedded systems design and exploration of energy-reliability tradeoffs for Systems on Chip and Embedded Systems. His research interests span across the emerging areas of evolvable hardware and perceptual computing. 